\title{
PENGARUH LIKUIDITAS, LEVERAGE, DAN PROFITABILITAS TERHADAP HARGA SAHAM INDUSTRI MAKANAN DAN MINUMAN DI BEI
}

\author{
ALFRIDA RIANISARI \\ HUSNAH \\ CICI RIANTY K.BIDIN \\ Program Studi S1 Manajemen Fakultas Ekonomi Universitas Tadulako \\ EMAIL : alfridalerman19@gmail.com
}

\begin{abstract}
Absract
This study aims to determine the effect of simultaneous liquidity, leverage and profitability to stock prices and the partial influence of liquidity, leverage and profitability to stock prices in food and beverage industry listed on Indonesia Stock Exchange (IDX). This study uses the entire food and beverage industry population listed in Indonesia Stock Exchange (IDX) in 2012 until 2016 as many as 16 companies. Sampling is done by purposive sampling. The sample used in this study as many as 11 companies listed on the Indonesia Stock Exchange (IDX). Data analysis method used is panel data regression analysis using EViews 9 program. The results stated that during the period 2012-2016 (1) simultaneously liquidity, leverage and profitability have an effect on signifikan to stock price in food and beverage industry which listed in Indonesia Stock Exchange (IDX), (2) liquidity has a positive and significant effect on stock price, (3) leverage have positive and insignificant effect to stock price, (4) profitability has a positive and significant effect on stock prices in food and beverage industry listed in Indonesia Stock Exchange (IDX).
\end{abstract}

Keywords: Liquidity, Leverage, Profitability, Stock Price.

\begin{abstract}
Abstrak
Penelitian ini bertujuan untuk mengetahui pengaruh simultan likuiditas, leverage dan profitabilitas terhadap harga saham dan pengaruh parsial likuiditas, leverage dan profitabilitas terhadap harga saham pada industri makanan dan minuman yang terdaftar di Bursa Efek Indonesia (BEI). Penelitian ini menggunakan populasi seluruh industri makanan dan minuman yang terdaftar di Bursa Efek Indonesia (BEI) pada tahun 2012 sampai dengan 2016 sebanyak 16 perusahaan. Pengambilan sampel dilakukan dengan purposive sampling. Sampel yang digunakan dalam penelitian ini sebanyak 11 perusahaan yang terdaftar di Bursa Efek Indonesia (BEI). Metode analisis data yang digunakan adalah analisis regresi data panel dengan menggunakan program EViews 9. Hasil penelitian menyatakan bahwa selama periode 2012-2016 (1) secara simultan likuiditas, leverage dan profitabilitas berpengaruh signifikan terhadap harga saham pada industri makanan dan minuman yang terdaftar di Bursa Efek Indinesia (BEI), (2) likuiditas berpengaruh positif dan signifikan terhadap harga saham, (3) leverage berpengaruh positif dan tidak signifikan terhadap harga saham, (4) profitabilitas berpengaruh positif dan signifikan terhadap harga saham pada industri makanan dan minuman yang terdaftar di Bursa Efek Indinesia (BEI).
\end{abstract}

Kata Kunci: Likuiditas, Leverage, Profitabilitas, Harga Saham.

\section{PENDAHULUAN}

Pada era globalisasi saat ini salah satu indikator keberhasilan suatu negara dalam pembangunan adalah bergairahnya sektor usaha. Kemajuan pada sektor usaha dengan sendirinya memerlukan dana investasi yang cukup besar dalam rangka melakukan pengembangan-pengembangan usaha. Berkembangnya kegiatan usaha dalam bidang ekonomi saat ini menyebabkan perusahaan-perusahaan giat mencari sumber pembiayaan yang dapat menyediakan dana dengan jumlah yang lebih besar untuk memperluas kegiatan atau keperluan usahanya dan keperluan lainnya yaitu dengan cara menerbitkan kepemilikan sekuritas atau saham dengan menjualnya pada masyarakat umum melalui pasar modal. 


\section{Rianisari, A.}

Pasar modal merupakan salah satu alternatif pilihan sumber dana jangka panjang diantara berbagai alternatif lainnya bagi perusahaan. Dilihat dari perkembangannya, jumlah perusahaan yang menjual sahamnya di pasar modal semakin meningkat. Salah satunya perusahaan makanan dan minuman yang saat ini mengalami pertumbuhan yang signifikan dan juga termasuk dalam industri sangat kuat dari aktivitas perdagangan saham sehingga prospeknya menguntungkan baik masa sekarang maupun masa yang akan datang, selain itu saham perusahaan makanan dan minuman merupakan saham-saham yang paling tahan krisis ekonomi dibanding sektor lain.

Setiap perusahaan di sektor makanan dan minuman harus mampu bertahan dan bersaing di Bursa Efek Indonesia dikarenakan persaingan yang semakin meningkat. Perusahaan makanan dan minuman harus terus meningkatkan kinerja keuangan mereka agar mampu bersaing. Kinerja keuangan perusahaan dapat dinilai dengan melakukan analisis rasio keuangan yang terdapat dalam laporan keuangan.

Laporan keuangan tersebut memuat informasi mengenai kondisi dan keadaaan perusahaan pada periode tertentu juga berisi informasi tentang keadaan yang menyangkut kinerja keuangan yang efisien serta efektif. Untuk itu dari penelitian ini bahwa kinerja keuangan menggunakan rasio keuangan agar bisa menilai baik buruknya kinerja perusahaan dan hanya menggunakan tiga rasio keuangan yaitu rasio likuiditas, leverage, dan profitabilitas.

Likuiditas merupakan rasio yang menggambarkan kemampuan perusahaan dalam memenuhi kewajiban jangka pendeknya yang segera jatuh tempo dan likuiditas diukur menggunakan Current Ratio (Rasio Lancar), leverage merupakan rasio yang menggambarkan kemampuan perusahaan dalam memenuhi seluruh kewajibannya dan leverage diukur menggunakan Debt Ratio (Rasio Hutang), profitabilitas merupakan hasil bersih dari sejumlah kebijakan atas keputusan perusahaan dan profitabilitas diukur menggunakan Return on Equity (Rasio Pengembalian atas Ekuitas) (Hery, 2016).

\section{KAJIAN LITERATUR DAN PENGEMBANGAN HIPOTESIS}

1. Likuiditas, leverage dan profitabilitas secara simultan berpengaruh signifikan terhadap harga saham pada Industri Makanan dan Minuman di Bursa Efek Indonesia.

2. Likuiditas secara parsial berpengaruh signifikan terhadap harga saham pada Industri Makanan dan Minuman di Bursa Efek Indonesia.

3. Leverage secara parsial berpengaruh signifikan terhadap harga saham pada Industri Makanan dan Minuman di Bursa Efek Indonesia.

4. Profitabilitas secara parsial berpengaruh signifikan terhadap harga saham pada Industri Makanan dan Minuman di Bursa Efek Indonesia.

\section{Penelitian Terdahulu}

Adriana Kundiman (2016), melakukan penelitian yang berjudul "pengaruh Current Ratio, Debt To Equity Ratio, Return On Asset, Return On Equity terhadap Harga Saham pada Indeks Lq 45 di Bursa Efek Indonesia Periode 2010-2014”. Penelitian ini bertujuan untuk mengetahui pengaruh Current Ratio, Debt To Equity Ratio, Return On Asset, Return On Equity terhadap Harga Saham pada Indeks Lq 45 di Bursa Efek Indonesia Periode 2010-2014. Hasil penelitian menunjukkan bahwa secara parsial variabel CR, DER, ROA berpengaruh positif dan signifikan terhadap harga saham dan ROE tidak berpengaruh signifikan terhadap harga saham. Sedangkan secara simultan CR, DER, ROA dan ROE berpengaruh signifikan terhadap harga saham.

Sri Wahyuni (2016), melakukan penelitian yang berjudul "analisis pengaruh rasio profitabilitas terhadap harga saham pada perusahaan Food And Beverages dan Consumers Goods yang terdaftar di Bursa Efek Indonesia tahun 2011-2014". Tujuan penelitian ini untuk menganalisa pengaruh Return On Assets (ROA), Return On Equity (ROE), Debt To Equity Return (DER), Earning Per Share (EPS), dan Net Profit Margin (NPM) terhadap harga saham perusahaan manufaktur yang terdaftar di Bursa Efek Indonesia tahun 2011-2014. Berdasarkan hasil penelitian secara parsial diketahui bahwa DER tidak 
berpengaruh secara signifikan dan positif terhadap harga saham. ROA, ROE, dan EPS berpengaruh signifikan dan positif terhadap harga saham. NPM berpengaruh signifikan dan negatif terhadap harga saham. Sedangkan secara simultan ROA, ROE, DER, EPS, dan NPM berpengaruh signifikan dan positif terhadap harga saham.

Fransisco F. G. Ginsu, et al (2017), melakukan penelitian yang berjudul "pengaruh Earning Per Share (EPS) dan Return On Equity (ROE) terhadap harga saham pada Industri food \& beverage yang terdaftar di Bursa Efek Indonesia periode 2013-2015". Penelitian ini bertujuan untuk mengetahui pengaruh Earning Per Share (EPS) dan Return On Equity (ROE) terhadap harga saham pada Industri Food \& Beverage yang terdaftar di Bursa Efek Indonesia periode 2013-2015. Hasil penelitian menunjukkan bahwa variabel Earning Per Share (EPS) memiliki pengaruh positif tetapi tidak signifikan terhadap harga saham dan variabel Return On Equity (ROE) memiliki pengaruh positif tetapi tidak signifikan terhadap harga saham.

Febriawan Arie Nugroho (2017), melakukan penelitian yang berjudul "pengaruh rasio profitabilitas dan likuiditas terhadap harga saham pada Perusahaan Manufaktur yang terdaftar di Jakarta Islamic Index". Penelitian ini bertujuan untuk menganalisis pengaruh Current Ratio, Quick Ratio, Cash Ratio, Gross Profit Margin, Return on Asset dan Return on Equity terhadap harga saham pada perusahaan manufaktur yang terdaftar di Jakarta Islamic Index. Berdasarkan hasil penelitian variabel Quick Ratio, Gross Profit Margin dan Return on Asset mempunyai pengaruh signifikan secara parsial terhadap harga saham, sedangkan variabel Current Ratio, Cash Ratio dan Return on Equity tidak mempunyai pengaruh secara parsial terhadap harga saham.

Dewanto, dkk (2017) dalam penelitiannya mengemukakan bahwa Debt ratio, times interest earned ratio, long-term debt to equity ratio, ROA, ROE dan NPM tidak berpengaruh signifikan terhadap nilai perusahaan industri makanan dan minuman yang terdaftar di BE

Cristin Oktavia Tumandung, et al (2017) melakukan penelitian yang berjudul "analisis pengaruh kinerja keuangan terhadap harga saham pada Perusahaan Makanan dan Minuman yang terdaftar di BEI periode 2011-2015”. Penelitian ini bertujuan untuk mengetahui apakah kinerja keuangan yang diukur dengan rasio keuangan current ratio (CR), return on equity (ROE), debt to equity ratio (DER), dan total asset turn over (TATO) berpengaruh signifikan terhadap harga saham. Hasil penelitian menunjukkan bahwa secara persial hanya return on equity dan debt to equity ratio berpengaruh signifikan terhadap harga saham, sedangkan secara simultan menunjukan bahwa keempat variabel yang di gunakan yaitu current ratio, return on equity, debt to equity ratio dan total asset turn over berpengaruh secara signifikan terhadap harga saham.

\section{Rasio Keuangan}

Rasio keuangan menggambarkan suatu hubungan atau perimbangan (mathematical relationship) antara suatu jumlah tertentu dengan jumlah yang lain, dan dengan menggunakan alat analisa berupa rasio ini akan dapat menjelaskan atau memberi gambaran kepada penganalisa tentang baik atau buruknya keadaan atau posisi keuangan suatu perusahaan terutama apabila angka rasio pembanding yang digunakan standar (Munawir, 2014:64).

\section{Rasio Likuiditas}

Rasio likuiditas adalah rasio yang digunakan untuk mengukur tingkat keamanan kreditor jangka pendek, serta mengukur apakah operasi perusahaan tidak akan terganggu bila kewajiban jangka pendek ini segera ditagih. Rasio likuiditas yang akan diteliti adalah current ratio (CR) yaitu rasio yang membandingkan antara aktiva lancar yang dimiliki perusahaan dengan kewajiban jangka pendek. Menurut (Brigham, 2012: 134) Current Ratio (CR) merupakan sebuah rasio likuiditas yang menunjukan sampai sejauh apa kewajiban lancar ditutupi oleh aset yang diharapkan akan dikonversi menjadi kas dalam waktu dekat.

\section{Rasio Leverage}

Leverage merupakan penggunaan aktiva atau dana dimana untuk penggunaan tersebut harus 


\section{Rianisari, A.}

menutup atau membayar beban tetap. Leverage tersebut menunjukkan proporsi atas penggunaan utang untuk membiayai investasinya. Rasio ini merupakan perbandingan antara hutang lancar dan hutangjangka panjang dan jumlah seluruh aktiva diketahui. Rasio ini menunjukkan berapa bagian dari keseluruhan aktiva yang dibelanjai oleh hutang (Harahap, 2011:303). Leverage diukur dengan Debt ratio (Rasio Hutang) merupakan rasio yang menggambarkan seberapa besar proporsi hutang dalam membiayai aktiva perusahaan dan juga memberikan informasi seberapa besar resiko keuangan bagi perusahaan.

\section{Rasio Profitabilitas}

Rasio profitabilitas merupakan rasio untuk menilai kemampuan perusahaan dalam mencari keuntungan. Rasio ini juga memberikan ukuran tingkat efektivitas manajemen suatu perusahaan (Kasmir 2012:196). Sementara itu profitabilitas dapat pula diartikan sebagai penambahan Equity pemilik yang terjadi karena keberhasilan dalam operasi bisnis. Atau kemampuan bisnis suatu badan usaha menghasilkan neto. Diantara beberapa ukuran profitabilitas, pengembalian modal atau Return On Equity merupakan salah satu ukuran profitabilitas yang digunakan untuk mengukur kemampuan perusahaan dalam pemperoleh laba dari setiap modal yang ditanamkan oleh pemilik perusahaan.

\section{Harga Saham}

Harga saham merupakan salah satu indikator keberhasilan pengelolaan perusahaan perbankan, karena jika harga saham suatu perusahaan mengalami kenaikan, akan banyak investor yang tertarik untuk berinvestasi di perusahaan, objek dalam penelitian ini yaitu perusahaan perbankan. Samsul (2015) menjelaskan harga saham selama jam perdagangan bergerak naik/turun dalam setiap detiknya. Harga tersebut dapat terbentuk puluhan kali dalam waktu sehari perdagangan untuk satu jenis saham.

\section{METODE PENELITIAN}

Penelitian ini dilakukan dengan menggunakan metode deskriptif-verifikatif yang dimaksudkan untuk menjelaskan fenomena-fenomena yang terjadi pada objek penelitian secara luas tentang permasalahan yang diteliti dengan menggunakan alat dan data statistik ekonometrik sebagai pembukian hipotesis dari permasalahan sehingga dapat ditarik sebuah kesimpulan teoritis yang bias menjawab permasalahan yang ada. Fenomena yang ingin dijelaskan disini adalah bahwa harga saham yang fluktuatif dipengaruhi oleh profitabilitas, leverage, dan likuiditas.

\section{Lokasi dan Waktu Penelitian}

Lokasi penelitian adalah pada Bursa Efek Indonesia (BEI) Jakarta dengan mengunduh data resmi Bursa Efek Indonesia (BEI) yaitu Indonesia Stok Exchange (IDX) di www.idx.co.id dan Indonesian Capital Market Directory (ICMD). Unit analisis dalam penelitian ini merupakan organisasi berupa perusahaan makanan dan minuman pada Bursa Efek Indonesia pada tahun 2012-2016.

\section{Metode Pengumpulan Data}

Pengumpulan data dilakukan dengan menggunakan metode dokumentasi, yaitu pengambilan atau pengumpulan dokumen-dokumen laporan keuangan tahunan perusahaan makanan dan minuman di Bursa Efek Indonesia periode 2012-2016. Sugiyono, (2013:240) dokumentasi merupakan catatan peristiwa yang sudah berlalu. Dokumen bisa berbentuk tulisan, gambar, atau karya-karya monumental dari seorang. Dokumen yang berbentuk tulisan misalnya catatan harian, sejarah kehidupan (life histories), ceritera, biografi, peraturan, kebijakan.

\section{Analisis Regresi Data Panel}

Metode analisis dalam penlitian ini menggunakan analisis regresi data panel untuk memperoleh gambaran menyeluruh mengenai hubungan variabel satu dengan variabel yang lain. Variabel dependent adalah harga saham (Y) dan variabel independent adalah Likuiditas (X1), Leverage (X2), dan Profitabilitas (X3). Untuk mengetahui apakah ada pengaruh yang signifikan dari variabel independent terhadap dependent maka maka digunakan metode analisis kuantitatif yaitu dengan menggunakan data panel, yaitu kombinasi antara deret waktu (time series) dan kerat lintang (cross 
section). Alat pengolahan data dengan menggunakan program Eviews 9. Persamaan regresi data panel adalah sebagai berikut:

$\boldsymbol{Y}_{i t}: \boldsymbol{\beta}_{0}+\boldsymbol{\beta}_{1} \boldsymbol{X}_{1 i t+} \boldsymbol{\beta}_{2} \boldsymbol{X}_{2 i t}+\boldsymbol{\beta}_{3} \boldsymbol{X}_{3 i t}+\boldsymbol{e}_{i t}$

\section{HASIL DAN PEMBAHASAN}

\section{Uji Normalitas Data}

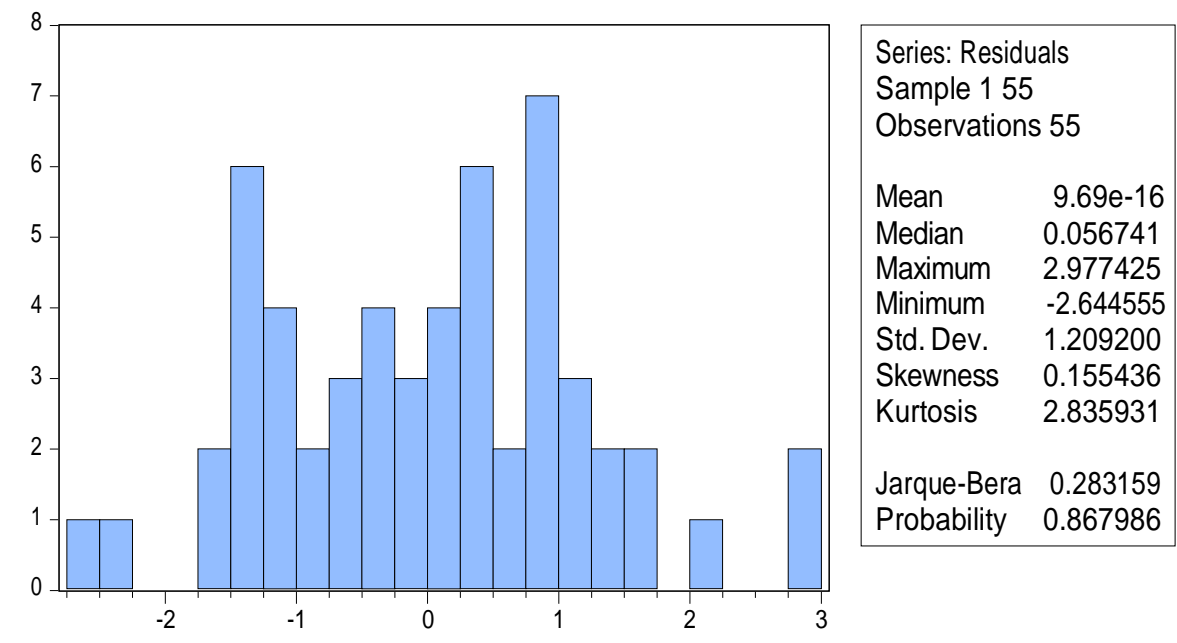

Gambar 1

Uji normalitas memiliki tujuan untuk menguji apakah dalam model regresi, variabel pengganggu atau residual memiliki distribusi normal. Jika terdapat normalitas, maka residual akan terdistribusi secara normal dan independen yaitu perbedaan antara nilai prediksi dengan skor yang sesungguhnya atau error akan terdistribusi secara simetri di sekitar nilai mean sama dengan nol (Ghozali,2013). Berdasarkan pada gambar 1 diatas uji normalitas dengan menggunakan pengujian jarque-berra. Hasil pengujian menunjukkan bahwa nilai p-Jarque-Berra sebesar 0.283159 yaitu berarti lebih besar dari $5 \%(0.283159>0.05)$ dengan demikian data memenuhi syarat normalitas.

\section{Uji Autokorelasi}

Tabel 1

\section{Uji Autokorelasi}

Breusch-Godfrey Serial Correlation LM Test:

\begin{tabular}{|c|c|c|c|}
\hline F-statistic & 2.479336 & Prob. F(2,49) & 0.0943 \\
\hline Obs*R-squared & 5.054368 & Prob. Chi-Square(2) & 0.0799 \\
\hline
\end{tabular}

Autokorelasi adalah keadaan dimana faktor-faktor pengu antara satu dengan yang lain saling berhubungan, atau dengan kata lain uji korelasi ini dilakukan untuk mengetahui adanya kolerasi antara anggota serangkaian data observasi time series maupun data cross section. Berdasarkan tabel 1 diketahui bahwa nilai Chi Square > 0,05; maka tidak terjadi Autokorelasi.

\section{Uji Heteroskedastisitas}

Tabel 2

\section{Hasil Uji Heteroskedastisitas}

Heteroskedasticity Test: White

\begin{tabular}{|l|l|l|l|}
\hline F-statistic & 1.999244 & Prob. F(3,51) & 0.1258 \\
\hline Obs*R-squared & 5.787516 & Prob. Chi-Square(3) & 0.1224 \\
\hline Scaled explained SS & 4.568078 & Prob. Chi-Square(3) & 0.2063 \\
\hline
\end{tabular}


Uji bertujuan menguji apakah dalam model regresi terjadi ketidaksamaan varians dari residual suatu pengamatan ke pengamatan lain. Berdasarkan tabel 2 diketahui bahwa nilai $p$-value $O b s * R$ square 0.1224 . Nilai ini lebih besar dari pada alfa $0,05(5 \%)$ yang berarti bahwa model regresi tidak memiliki masalah heteroskedastisitas.

\section{Uji Multikolinearitas}

\section{Tabel 3}

Uji Multikolinearitas

\begin{tabular}{|c|c|c|c|}
\hline & Likuiditas (CR) & Leverage (DR) & Profitabilitas (ROE) \\
\hline Likuiditas (CR) & 1.000000 & -0.838078 & -0.182598 \\
\hline Leverage (DR) & -0.838078 & 1.000000 & 0.015482 \\
\hline Profitabilitas (ROE) & -0.182598 & 0.015482 & 1.000000 \\
\hline
\end{tabular}

Uji multikolinearitas bertujuan untuk menguji apakah model regresi ditemukan adanya korelasi antar variabel bebas (independen). Model regresi yang baik seharusnya tidak terjadi korelasi di antara variabel independen. Berdasarkan tabel 3 dapat diketahui bahwa setiap variabel memiliki nilai dibawah 0,8 , sehingga dapat disimpulkan tidak terjadi multikolinearitas.

\section{Uji Regresi Data Panel}

\section{Tabel 4}

Ringkasan Hasil Uji Regresi Data Panel (EViews)

\begin{tabular}{|c|c|c|c|c|}
\hline Variable & Coefficient & Std. Error & t-Statistic & Prob. \\
\hline C & 10.02641 & 0.940772 & 10.65764 & 0.0000 \\
\hline Likuiditas (CR) & 1.462215 & 0.662752 & 2.206280 & 0.0319 \\
\hline Leverage (DR) & 1.196891 & 1.051913 & 1.137823 & 0.2605 \\
\hline Profitabilitas (ROE) & 1.066784 & 0.349571 & 3.051692 & 0.0036 \\
\hline
\end{tabular}

$\boldsymbol{Y}_{i t}=\boldsymbol{\beta}_{0}+\beta_{1} X_{1 i t}+\beta_{2} X_{2 i t}+\beta_{3} X_{3 i t}+e_{i t}$

$Y_{i t}=10.02641+1.462215\left(X_{1}\right)+1.196891\left(X_{2}\right)+1.066784\left(X_{3}\right)$

\section{KESIMPULAN DAN SARAN}

\section{Kesimpulan}

Berdasarkan hasil penelitian dan analisis yang dilakukan pada industri Makanan dan Minuman yang go public di Bursa Efek Indonesia pada periode tahun 2012 sampai 2016 dapat disimpulkan sebagai berikut :

1. Likuiditas, leverage, dan profitabilitas secara simultan berpengaruh secara signifikan terhadap Harga Saham pada perusahaan indutri makanan dan minuman di Bursa Efek Indonesia periode tahun 2012-2016.

2. Likuiditas secara parsial berpengaruh signifikan terhadap harga saham pada indutri makanan dan minuman di Bursa Efek Indonesia. Likuiditas mempunyai hubungan yang positif dengan harga saham.

3. Leverage secara parsial tidak berpengaruh signifikan terhadap harga Saham pada perusahaan indutri makanan dan minuman di Bursa Efek Indonesia. Leverage mempunyai hubungan positif dengan harga saham.

4. Profitabilitas secara parsial berpengaruh signifikan terhadap harga Saham pada perusahaan indutri makanan dan minuman di Bursa Efek Indonesia. Profitabilitas mempunyai hubungan positif dengan harga saham. 


\section{Saran}

1. Bagi perusahaan industri makanan dan minuman sebaiknya meningkatkan pengelolaan keuangan mereka dengan meningkatkan rasio-rasio keuangan mereka seperti likuiditas dan profitabilitas agar harga pasar saham perusahaan dipasar modal mengalami peningkatan. Hasil penelitian menunjukkan bahwa likuiditas dan profitabilitas perusahaan yang tinggi akan direspon dengan baik oleh para investor di pasar modal sehingga hal ini akan mengakibatkan harga saham perusahaan di pasar modal mengalami kenaikan.

2. Bagi calon investor perlu melihat peningkatan likuiditas dan profitabilitas yang berpengaruh signifikan terhadap harga saham. Peningkatan kedua variabel tersebut dapat dilakukan dengan cara seperti selalu memperhatikan posisi aset lancar dan hutang lancar sehingga likuiditas perusahaan yang diukur dengan Current Ratio selalu dalam keadaan yang baik dan melakukan kegiatan operasi dengan cara memanfaatkan ekuitas yang ada seefisien mungkin sehingga selalu menghasilkan laba yang tinggi sehingga nilai rasio profitabilitas yang diukur dengan Return On Equity juga akan baik.

3. Bagi penelitian selanjutnya adalah untuk memperbesar populasi, tidak hanya di satu sektor saja, guna menambah daya generalisasi terhadap hasil penelitian yang telah dilakukan. Sehingga hasil penelitiannya menjadi lebih relevan untuk dijadikan acuan dalam berinvestasi bagi investor ataupun calon investor di Indonesia. Bagi Investor, dalam mengambil keputusan berinvestasi saham pada perusahaan, dapat memperhatikan kinerja keuangan perusahaan melalui rasio-rasio keuangan yang memiliki pengaruh secara signifikan terhadap harga saham. Berdasarkan penelitian ini rasio-rasio yang berpengaruh secara signifikan terhadap harga saham yaitu likuiditas dan Profitabilitas.

\section{REFERENSI}

Brigham (2012). Dasar-dasar Manajemen Keuangan. Edisi Kesebelas. Jakarta: Salemba Empat.

Dewanto, Alfret Kristanto, Muslimin, Yunus Kasi, (2017), "Pengaruh Rasio Leverage dan Profitabilitas Terhadap Nilai Perusahaan Industri Makanan dan Minuman Yang Terdaftar Di Bursa Efek Indonesia”, Jurnal Ilmu Manajemen Univeristas Tadulakko, Vol. 3 No.1, Januari 207.

Ginsu, et al (2017), "Pengaruh Earning Per Share (EPS) dan Return On Equity (ROE) terhadap harga saham pada Industri food \& beverage yang terdaftar di Bursa Efek Indonesia periode 20132015”. Jurnal EMBA, Vol. 5, No.2,Hal 1327-1336.

Ghozali, Imam. 2013. Aplikasi Analisis Multivariate dengan Program SPSS. Edisi Ketujuh. Semarang: Badan Penerbit Universitas Diponegoro.

Harahap 2011. Teori Akuntansi . Edisi Revisi 2011. Jakarta: Rajawali Pers.

Hery, 2016. Analisis Laporan Keuangan. Jakarta: PT. Grasindo.

Kasmir.(2012). Analisis Laporan Keuangan. Jakarta: PT. Raja Grafindom Persada.

Kundiman, Adriana (2016), "pengaruh Current Ratio, Debt To Equity Ratio, Return On Asset, Return On Equity terhadap Harga Saham pada Indeks Lq 45 di Bursa Efek Indonesia Periode 20102014”. Jurnal Among Makarti, Vol. 9, No.18, Hal 80-96.

Munawir. 2014. Analisa Laporan Keuangan. Edisi Keempat. Yogyakarta: Penerbit Liberty.

Nugroho, Febriawan Arie (2017), "Pengaruh rasio profitabilitas dan likuiditas terhadap harga saham pada perusahaan manufaktur yang terdaftar di Jakarta Islamic Index". Jurnal Ekonomi: Fakultas Ekonomi Universitas Muhammadiyah Surakarta : skripsi yang tidak dipublikasikan.

Samsul, M. (2015). Pasar Modal dan Manajemen Portofolio. Jakarta: Erlangga.

Sugiyono.2013. Metodologi Peneitian Bisnis. Cetakan Kedua. Bandung: Penerbit Alfabeta..

Tumandung, et al. (2017), "Analisis pengaruh rasio profitabilitas terhadap harga saham pada perusahaan food and beverages dan consumers goods yang terdaftar di Bursa Efek Indonesia 
Rianisari, A.

tahun 2011-2014”. Jurnal EMBA, Vol. 5, No.2, Hal 1728-1737. 
Wahyuni, Sri (2016), “Analisis pengaruh rasio profitabilitas terhadap harga saham pada perusahaan food and beverages dan consumers goods yang terdaftar di Bursa Efek Indonesia tahun 20112014”. Jurnal Ekonomi: Fakultas Ekonomi Universitas Muhammadiyah Surakarta: skripsi yang tidak dipublikasikan. 